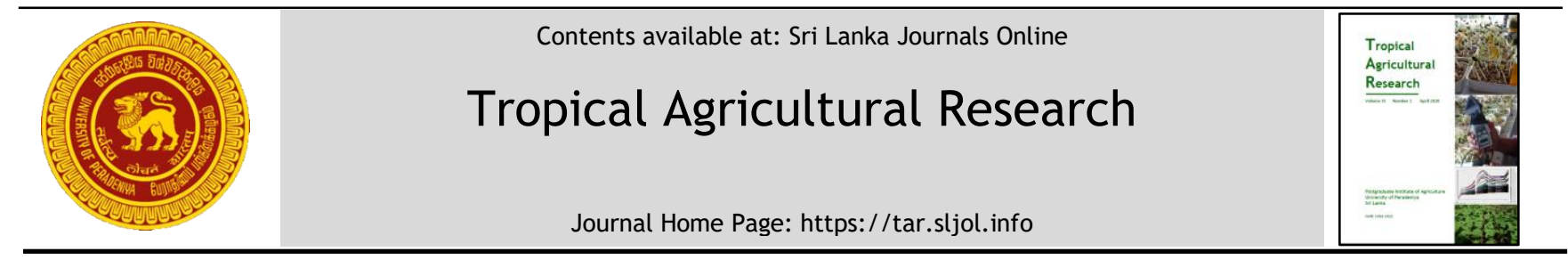

\title{
Application of Polyphasic OJIP Chlorophyll Fluorescent Transient Analysis as an Indicator for Testing of Seedling Vigour of Common Bean (Phaseolus vulgaris L.)
}

\author{
R.A.I.S. Ariyarathna $1^{*}$, S.L. Weerasena ${ }^{1}$ and C.K. Beneragama ${ }^{1,2}$ \\ 1 Postgraduate Institute of Agriculture, University of Peradeniya, Sri Lanka \\ ${ }^{2}$ Department of Crop Science, Faculty of Agriculture, University of Peradeniya, Sri Lanka
}

\section{ARTICLE INFO}

\section{Article history:}

Received: 23 September 2019

Accepted: 08 November 2019

Available online: 1 April 2020

\section{Keywords:}

Performance index

Quantum efficiencies

Seed vigour

Specific fluxes

Standard germination

\section{Citation:}

Ariyarathna, R.A.I.S., Weerasena, S.L. and Beneragama, C.K. (2020). Application of Polyphasic OJIP Chlorophyll Fluorescent Transient Analysis as an Indicator for Testing of Seedling Vigour of Common Bean (Phaseolus vulgaris L.). Tropical Agricultural Research, 31(2): 106-115.

DOI: http://doi.org/10.4038/tar.v31i2.8372

Ariyarathna, R.A.I.S. (D)

https://orcid.org/0000-0003-1445-9552

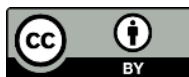

\begin{abstract}
In many stored seeds, even though the standard germination stays high with storage time the field emergence may not always be so. This makes the standard germination test results questionable in a commercial setting. The OJIP test derived from the polyphasic transient fluorescence is used as a latest method to determine the quality of seeds. We tested the suitability of this test to determine vigour of seeds of two Phaseolus varieties. Seeds of two varieties were stored in bulk in two different packing materials at controlled temperature $\left(17 \pm 1{ }^{\circ} \mathrm{C}\right)$ and relative humidity (52-55\%) for one year, and the seed germination and the field emergence were evaluated once in two months. The OJIP chlorophyll fluorescence parameters were measured in the first two leaves of 5-day old seedlings. Standard germination test results were acceptable even after one-year of storage. However, field emergence percentage reduced over storage time. Analysed data showed that OJIP derived parameters; specific energy fluxes (ABS/RC, $\left.\mathrm{TR}_{0} / \mathrm{RC}, \mathrm{ET}_{0} / \mathrm{RC}\right)$, quantum efficiencies (Phi_P0, Psi_0 , Phi_E0) and performance index (PIABS) were significantly different with the storage period. $\mathrm{PI}_{\mathrm{ABS}}$ did not differ significantly with variety and packing materials. $\mathrm{PI}_{\mathrm{ABS}}$ significantly correlated with the field emergence. As the reduction of $\mathrm{PI}_{\mathrm{ABS}}$ in the seedlings is due to the changes in physiological condition of the seeds at the seed storage, it can be used as a good indicator in assessing seed quality, seed vigour in particular.
\end{abstract}

*Corresponding author : Indira.ariyarathna@gmail.com 


\section{INTRODUCTION}

Seeds are the units of propagation of most agricultural crops all over the world. Seeds having good germinability and successful field emergence will lead to a proper crop establishment which is a significant sign of the ultimate yield. Seed storage conditions play a significant role on seed quality parameters (UNDP reports, 2007-08). The assessment of the germination and the identification of high performance of seed lots in storage is a key initiative towards successful crop production. Standard germination test results generated by a seed laboratory do not always represent the true physiological potential of the tested seed lots (Marcos-Filho, 2015). Various researchers have reported that the laboratory standard germination test is not a good indicator of field emergence (Aliloo, 2011; Morad, 2013). This is apparently disadvantageous for commercial farmers, thus it is of paramount importance to inspect the pre-field performance under laboratory conditions before releasing the seed lots to the growers.

Seed physiological potential comprises of germination, viability and vigour. These parameters indicate the capacity of seeds to perform their vital functions under both favorable and unfavorable environmental conditions (Marcos-Filho, 2015). There is no universally accepted single method for assessing seed physiological potential of a given species or group of species. For this reason, research correlating laboratory seed testing to field emergence have been considered important.

Seed vigor testing provides a precise identification of differences in physiological potential of seeds which is not detected by the standard germination test. Various techniques are available to determine seed vigor directly or indirectly. These include physiological assessments (e.g. rate of germination, radicle emergence test, and stress test), biochemical assessments (e.g. conductivity test, tetrazolium test) and assessment of the aging process (e.g. accelerated aging test, controlled deterioration test) (Adkins et al., 1996). Computer-assisted image analysis of seedlings (McCormac, et al., 1990) and automated seed vigor imaging system (Sako et al., 2001) are also amongst the early attempts to determine seedling vigor on some species.

As an indirect measurement of seed and seedling vigor, the evaluation of chlorophyll fluorescence is considered a promising method to determine the physiological potential of individual seeds (Cicer, et al., 2009; Dell'Aquilla, 2009). Immature seeds usually carry a considerable amount of chlorophylls (Jalink et al., 1998), while seed chlorophyll content reduces with seed maturation.

Many researchers have suggested that chlorophyll fluorescence is a tool to study the photosynthetic mechanism and plant performance under abiotic stress conditions (Longenberger et al., 2009). The most useful chlorophyll fluorescence methods are saturation pulse method, slow fluorescence kinetics, relative fluorescence decrease and fast chlorophyll fluorescence induction kinetics (Schreiber et al., 1986; Strasser et al., 1995; Schreiber, 2004).

Polyphasic chlorophyll fluorescence transient analysis, also known as OJIP test is a nondestructive, highly sensitive, fast and easily measurable, thus a widely used method in photosynthetic research (Brestic and Zivcak, 2013). Illumination of dark- adapted photosynthetic samples leads to emission of the chlorophyll $a$ fluorescence with a characteristic transient well known as the Kautsky curve (Kautsky and Hirsch, 1931). Chlorophyll fluorescence induction represents a plot of measured fluorescence intensity as a function of time of continuous illumination for milliseconds. Such a curve measured under continuous light, has a fast exponential phase and a slow decay phase. The initial growing phase shows a typical polyphasic shape when the curve is plotted on the logarithmic time scale. This information can successfully be applied in evaluating the vigour of seeds and seedlings.

Therefore, the present research work was conducted to evaluate the possibility of using the OJIP test derived from the polyphasic transient chlorophyll fluorescence to predict the vigour of the seeds of two varieties of pole 
beans (Phaseolus vulgaris L.) by using the seedlings resulted from the standard germination test.

\section{MATERIALS AND METHODS}

Certified seed lots of two pole bean (Phaseolus vulgaris L.) varieties, 'Keppetipola Nil' (KN) and 'Bandarawela Green' (BG) stored in controlled temperature $\left(17 \pm 1^{\circ} \mathrm{C}\right)$ and relative humidity (RH) (52-55\%) were used for this study. Two seed lots of $28 \mathrm{~kg}$ each were packed in polypropylene and polysac bags separately and kept under the above conditions for one year. Samples were drawn every two months and subjected to the standard seed quality tests during this year.

Laboratory germination test was conducted according to the guidelines of the International Seed Testing Association (ISTA, 2015). Prescribed sand media was used to plant $25 \times 4$ seeds per germination tray and allowed to germinate inside a germination chamber at $25 \pm 1{ }^{\circ} \mathrm{C}$ with 8 hours of light. Number of germinated seeds was counted on the $5^{\text {th }}$ day as the first count and considered as standard germination and expressed as a percentage.

Field emergence was tested in Randomized Complete Block Design with three replicates.
For each replicate, 100 seeds were sown in well-pulverized soil. As per the ISTA guidelines, the normal seedlings which emerged at the $10^{\text {th }}$ day of the planting were counted and expressed as a percentage of field emergence.

\section{Chlorophyll fluorescence measurement}

Chlorophyll fluorescence was measured using FluorPen 100 fluorometer (PSI, Czech Republic) in the first two leaves of seedlings at the time of $5^{\text {th }}$ day of the seedlings germinated under laboratory conditions. The analysis of polyphasic OJIP chlorophyll fluorescent transients and related parameters (OJIP analysis) was performed using procedures described by Strasser et al., 2000.

The nomenclature for OJIP was as follows; 0 is for origin or $\mathrm{F}_{0}$ of which level measured at 50 $\mu \mathrm{s}$ or less after illumination; J and I represent the intermediate states measured after 2 and $30 \mathrm{~ms}$ respectively. Maximum fluorescence was denoted as $\mathrm{P}$ or $\mathrm{F}_{\mathrm{m}}$ (Figure 1).

Several parameters have been derived from the polyphasic chlorophyll transient analysis as shown in the Table 1.

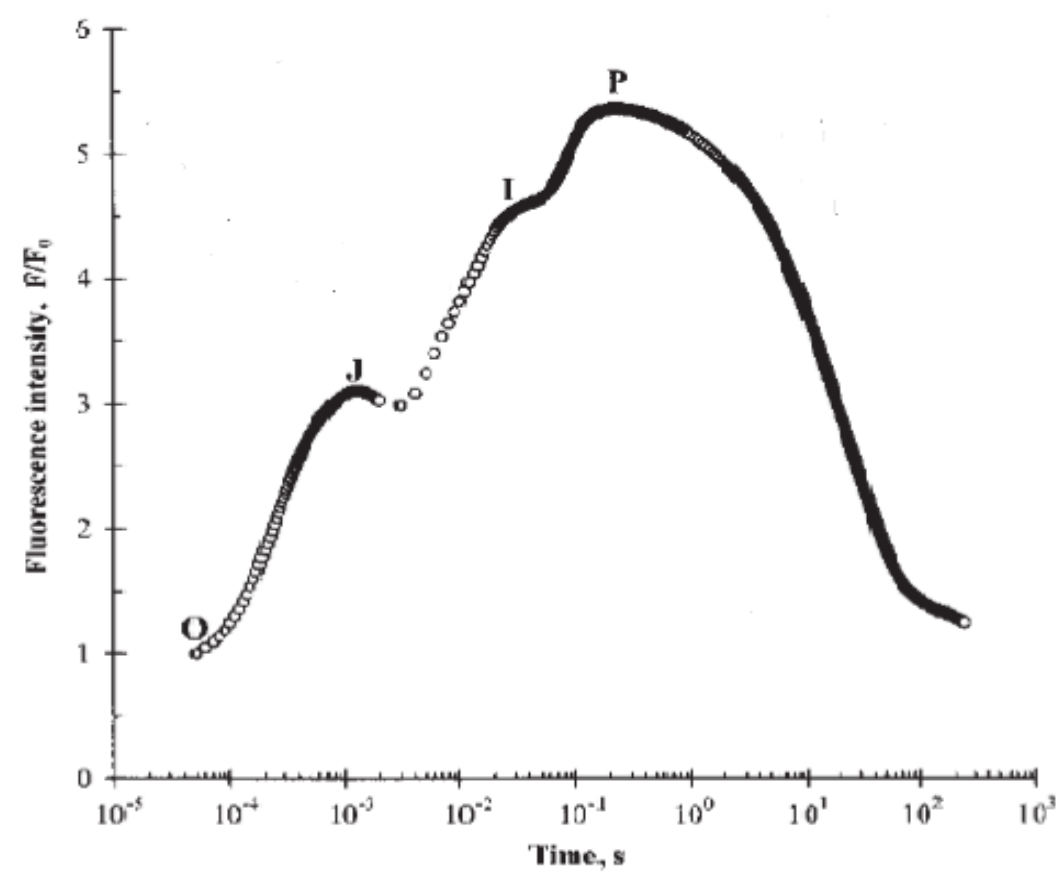

Figure 1: Typical OJIP transients of chlorophyll fluorescence plotted on logarithmic time scale. 
Table 1: Parameters derived from fast chlorophyll fluorescent transients (adapted from Strasser et al., 2000).

\begin{tabular}{|c|c|c|}
\hline Parameter & Name and basic physiological interpretation & Calculation \\
\hline \multicolumn{3}{|c|}{ Basic parameters from OJIP transients } \\
\hline $\mathrm{F}_{0}$ & $\begin{array}{l}\text { Minimum Fluorescence, when all RC PC II are } \\
\text { open (O-step of OJIP transient) }\end{array}$ & \\
\hline $\mathrm{F}_{\mathrm{M}}$ & Maximum fluorescence intensity & \\
\hline $\mathrm{F}_{\mathrm{V}}$ & Maximal variable fluorescence & $=\mathrm{F}_{\mathrm{M}}-\mathrm{F}_{0}$ \\
\hline $\mathrm{V}_{\mathrm{J}}$ & Relative variable fluorescence at the J step & $=\left(F_{J}-F_{0}\right)\left(F_{M}-F_{0}\right)$ \\
\hline $\mathrm{V}_{\mathrm{I}}$ & Relative variable fluorescence at the I step & $=\left(F_{I}-F_{0}\right)\left(F_{M}-F_{0}\right)$ \\
\hline $\mathrm{M}_{0}$ & $\begin{array}{l}\left.\text { Approximated initial slope (in } \mathrm{ms}^{-1}\right) \text { of } \\
\text { fluorescence transient } \mathrm{V}=\mathrm{f}(\mathrm{t})\end{array}$ & \\
\hline \multicolumn{3}{|c|}{ Specific energy fluxes } \\
\hline $\mathrm{ABS} / \mathrm{RC}$ & Absorption flux per RC & $=\mathrm{M}_{0}\left(1 / \mathrm{V}_{\mathrm{J}}\right)\left(1 / \varphi_{\mathrm{Po}}\right)$ \\
\hline $\mathrm{TR}_{0} / \mathrm{RC}$ & Trapped energy flux per $\mathrm{RC}$ at $\mathrm{t}=0$ & $=\mathrm{M}_{0}\left(1 / \mathrm{V}_{\mathrm{J}}\right)$ \\
\hline $\mathrm{ET}_{0} / \mathrm{RC}$ & Electron transfer flux per $\mathrm{RC}$ at $\mathrm{t}=0$ & $=\mathrm{M}_{0}\left(1 / \mathrm{V}_{\mathrm{J}}\right)\left(\mathrm{\varphi}_{\mathrm{o}}\right)$ \\
\hline \multicolumn{3}{|c|}{ Yields of flux ratios/Quantum efficiencies } \\
\hline$\varphi_{\text {Po }}=$ Phi_Po & $\begin{array}{l}\text { Maximum quantum yield of primary PS II } \\
\text { photochemistry }\end{array}$ & $\begin{array}{l}=\mathrm{TR}_{0} / \mathrm{ABS} \\
=1-\left(\mathrm{F}_{0} / \mathrm{F}_{\mathrm{M}}\right) \text { or } \mathrm{F}_{\mathrm{V}} / \mathrm{F}_{\mathrm{M}}\end{array}$ \\
\hline $\mathrm{p}_{\mathrm{o}}=$ Psi_o & $\begin{array}{l}\text { Probability at } t=0 \text { that a trapped excitation } \\
\text { moves on electron in to the electron transport } \\
\text { chain beyond } Q_{A^{-}}\end{array}$ & $=\mathrm{ET}_{0} / \mathrm{TR}_{0}=\left(1-\mathrm{V}_{\mathrm{j}}\right)$ \\
\hline$\varphi_{\text {Eo }}=$ Phi_Eo & Quantum yield of electron transport at $\mathrm{t}=0$ & $\begin{array}{l}=\mathrm{ET}_{0} / \mathrm{ABS} \\
=\left[1-\left(\mathrm{F}_{0} / \mathrm{F} \mathrm{F}_{\mathrm{M}}\right)\right]\end{array}$ \\
\hline$P I_{A B S}$ & $\begin{array}{l}\text { Performance index for the photochemical } \\
\text { activity(basic formula on absorption basis) }\end{array}$ & $\begin{aligned}= & (\mathrm{RC} / \mathrm{ABS}) \cdot\left(\varphi_{\mathrm{Po}} /(1-\right. \\
& \left.\varphi_{\mathrm{Po}}\right) \cdot\left(\vartheta_{\mathrm{o}} /\left(1-\varphi_{\mathrm{o}}\right)\right.\end{aligned}$ \\
\hline
\end{tabular}

Data were analyzed using the SAS (V9 for Windows) statistical analytical package and Graphpad prism8 software.

\section{RESULTS AND DISCUSSION}

Mean standard germination percentage and moisture of the seeds at the initial stage of both varieties are presented in the Table 2 . These values guarantee the quality of stored seeds used in the present study.

Bulk seeds of two varieties, Bandarawela Green (BG) and Keppetipola Nil (KN) packed in polypropylene and polysac bags displayed a high germination percentage throughout the storage period for one-year. Irrespective of the two packing materials, variety $\mathrm{KN}$ resulted a significantly lower mean germination percentage compared to the variety BG (Figure 2).

Table 2: Initial germination (\%) and seed moisture (\%) of two varieties of bean.

\begin{tabular}{lcc}
\hline Variety & $\begin{array}{c}\text { Standard } \\
\text { germination } \\
\%\end{array}$ & $\begin{array}{c}\text { Seed } \\
\text { moisture } \\
\%\end{array}$ \\
\hline $\begin{array}{l}\text { Bandarawela } \\
\text { Green (BG) }\end{array}$ & 100 & 11 \\
$\begin{array}{l}\text { Keppetipola Nil } \\
\text { (KN) }\end{array}$ & 98 & 11 \\
\hline
\end{tabular}



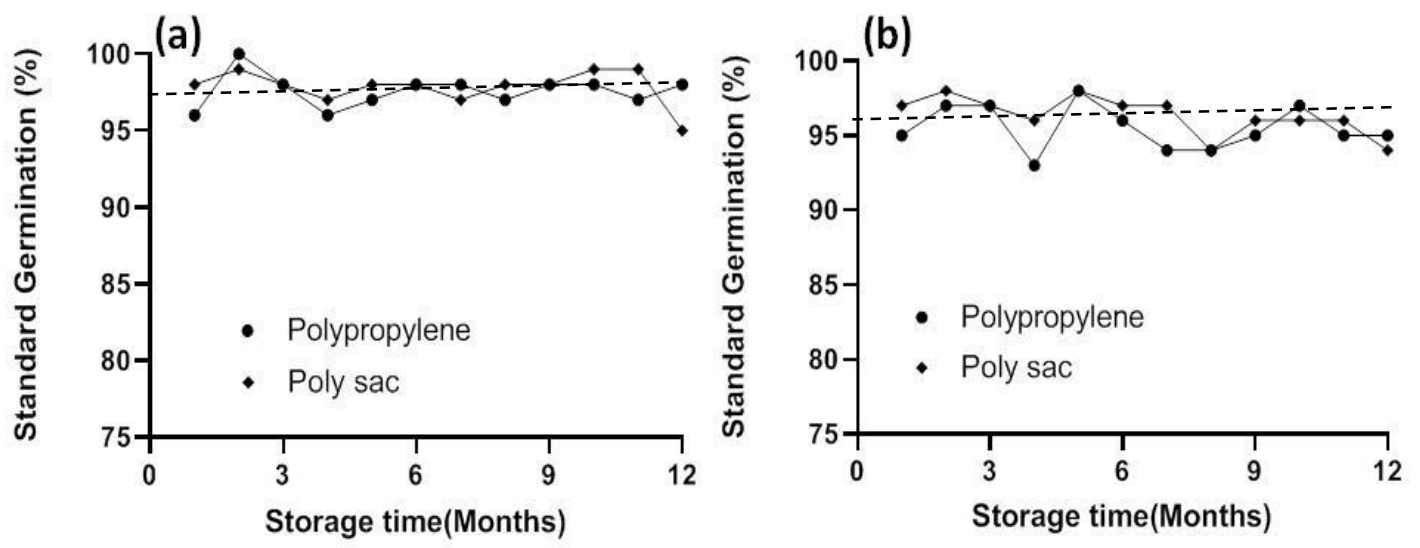

Figure 2: Standard germination percentage of beans packed in two packaging materials and stored under controlled temperature and RH conditions for one year; (a) variety Bandarawela Green (BG); (b) variety Keppetipola Nil (KN). Dashed line indicates the mean germination percentage over the 12 months period.

\section{Specific energy fluxes}

Effect of 12-month storage of seeds packed in different packing materials on specific energy fluxes of two varieties of bean seedlings are shown in Figure 3. Specific energy fluxes were significantly affected by time and variety of beans irrespective of the packing material (Table 3).

Total number of photons absorbed by chlorophyll molecules of all reaction centers per total number of active reaction centers denoted as ABC/RC showed an increase with storage period except variety $\mathrm{KN}$ stored in Polysac. The maximal rate by which an exciton is trapped by the RC $\left(\mathrm{TR}_{0} / \mathrm{RC}\right)$, and the maximal electron transfer between PS II and PS I per reaction center $\left(\mathrm{ET}_{0} / \mathrm{RC}\right)$ also increased along with that in seeds packed in polypropylene. As explained by Lawlor and Tezara (2009), the increase in specific fluxes is partly due to the small number of active RC in the PS II. According to Strasser and Srivastava (1995), increased ABS/RC on leaves with $\mathrm{N}$ deficiency indicates an increase of antenna size. In addition, inactivation of some PS II reaction centers can also be led to an increase ABS/RC (Lu et al., 2001; Castro et al., 2011). Therefore, it can be speculated that the increase of specific fluxes in seedlings in the present study may be due to the inactivation of some PS II RCs as seeds tend to deteriorate within the storage period.

\section{Quantum efficiencies}

Quantum efficiencies, the maximum quantum yield of primary PS II photochemistry $(\varphi \mathrm{Po}=\mathrm{Phi} P \mathrm{Po})$, the probability at $\mathrm{t}=0$ that a trapped excition moves on electron in to the electron transport chain beyond $\mathrm{Q}_{\mathrm{A}^{-}}(\mathrm{Po}=\mathrm{Psi} \mathrm{-} \mathrm{O})$ and quantum yield of electron transport at $\mathrm{t}=0$ $(\varphi$ Eo $=$ Phi_Eo) were analysed (Figure 4 and Table 3). All three parameters were significantly different with time irrespective of the packing materials. However, the Psi_0 was significantly different between the two varieities. Similar decrease in Phi_ $\mathrm{P}_{0}$ when exposed to severe stress conditons was reported by Manes et al. (2001) and Nussbaum et al. (2001).

\section{Performance Index (PI $\left.I_{\mathrm{ABS}}\right)$}

In the OJIP analysis, the performance index $\left(\mathrm{PI}_{A B S}\right)$ can be used to express the overall plant vitality and the performance (Strasser et al., 2000). Three independent parameters; density of fully active reaction centers (RCs), efficiency of electron movement by trapped exciton into the electron transport chain and the probability of that an absorbed photon will be trapped by RCs are used in determining the $\mathrm{PI}_{A B S}$. The lower $\mathrm{PI}_{\mathrm{ABS}}$ values reflect the lower vitality in photosynthetic tissues (Bussotti et al., 2006; Beneragama et al., 2014). 
Figure 5 shows a decreasing trend in $\mathrm{PI}_{A B S}$ with storage time in two bean varieties packed in two different packaging materials. Similarly, in our previous study of bean, the
$\mathrm{PI}_{A B S}$ of seedlings of 7-month old seeds of common bean showed a decreased $\mathrm{PI}_{A B S}$ values compared to those of fresh seeds (Bandulasena et al., 2017).
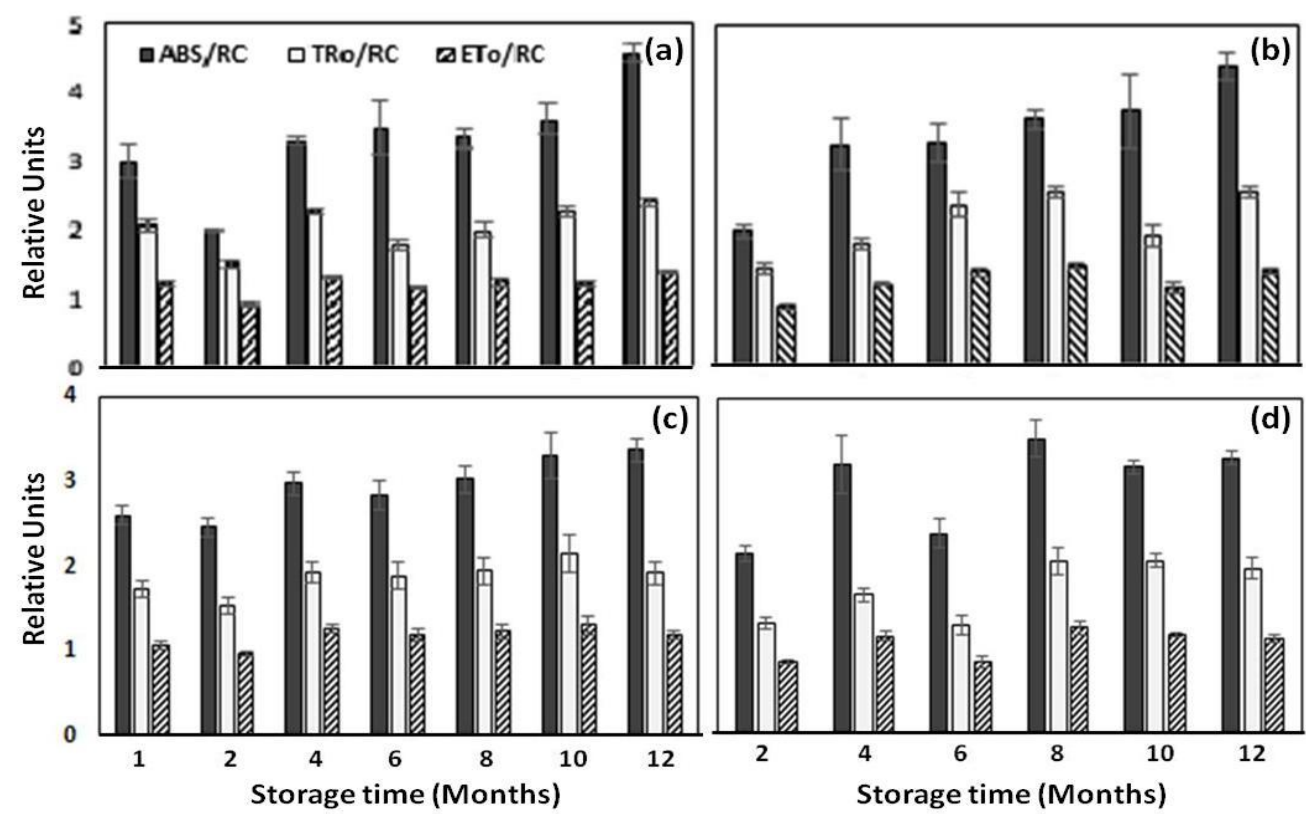

Figure 3: Specific energy fluxes measured in seedlings of two varieties of bean seeds packed in two packaging materials, during the 12-month storage period: ( $a$ and $b)$ variety Bandarawela Green (BG); (c and d) variety Keppetipola Nil (KN); ( $a$ and c) packed in polypropylene (b and d) packed in polysac. Means \pm SEM of absorption (ABS), trapping (TR) and electron transport (ET) per reaction center (RC) are given.
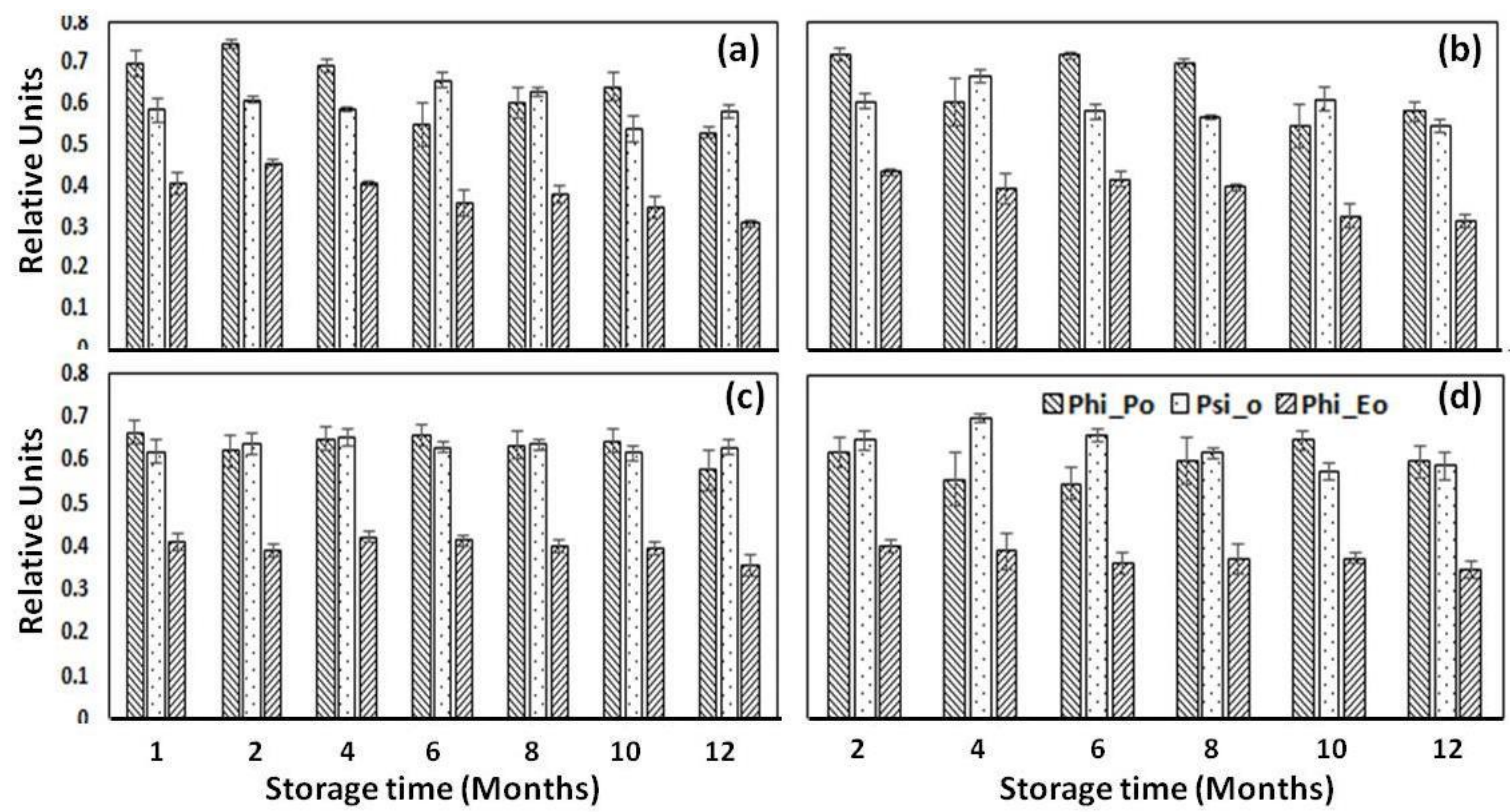

Figure 4: Quantum efficiencies measured in seedlings of two varieties of bean seeds packed in two packaging materials, during the 12-month storage period: $(a$ and $b)$ variety Bandarawela Green (BG); (c and d) variety Keppetipola Nil (KN); ( $a$ and c) packed in polypropylene (b and d) packed in polysac. Means \pm SEM of maximum quantum yield of primary PS II photochemistry (Phi_Po), probability at $\mathrm{t}=0$ that a trapped excition moves on electron in to the electron transport chain beyond QA- (Psi_o) and quantum yield of electron transport at $t=0$ (Phi_Eo) are given. 
Table 3: Derived OJIP parameters from polyphasic chlorophyll fluorescence transients in two bean varities BG and KN packed in polypropylene and polysac under contolled temperature and $\mathrm{RH}$.

\begin{tabular}{|c|c|c|c|c|c|c|c|}
\hline Time(months) & $\mathrm{ABS} / \mathrm{RC}$ & TRo/RC & ETo/RC & Phi_Po & Psi_o & Phi_Eo & Pi_Abs \\
\hline 1 & $2.5085^{d}$ & $1.74158^{b}$ & $1.04162^{\mathrm{cd}}$ & $0.69531^{\mathrm{a}}$ & $0.60419^{b}$ & $0.41800^{\mathrm{a}}$ & $1.5951^{\mathrm{a}}$ \\
\hline 2 & $2.4983^{d}$ & $1.55038^{c}$ & $0.99044^{d}$ & $0.64972^{\mathrm{a}}$ & $0.64342^{\mathrm{a}}$ & $0.41278^{\mathrm{a}}$ & $1.6267^{\mathrm{a}}$ \\
\hline 4 & $3.1728^{b c}$ & $1.90267^{b}$ & $1.23039^{\mathrm{ab}}$ & $0.62570^{\mathrm{cb}}$ & $0.65555^{\mathrm{a}}$ & $0.40561^{a}$ & $1.2598^{\mathrm{b}}$ \\
\hline 6 & $2.9320^{c}$ & $1.74296^{b}$ & $1.10812^{c}$ & $0.60658^{c b}$ & $0.64519^{a}$ & $0.38869^{\mathrm{ab}}$ & $1.1607^{\mathrm{bc}}$ \\
\hline 8 & $3.3755^{\mathrm{b}}$ & $2.13272^{\mathrm{a}}$ & $1.29628^{\mathrm{a}}$ & $0.63697^{b}$ & $0.61450^{\mathrm{b}}$ & $0.38908^{\mathrm{ab}}$ & $0.9545^{d c}$ \\
\hline 10 & $3.4603^{b}$ & $2.09631^{\mathrm{a}}$ & $1.20833^{b}$ & $0.62169^{c b}$ & $0.58711^{b}$ & $0.36250^{\mathrm{cb}}$ & $0.8490^{d}$ \\
\hline 12 & $3.8958^{\mathrm{a}}$ & $2.20531^{\mathrm{a}}$ & $1.27160^{\mathrm{ab}}$ & $0.57243^{c}$ & $0.58714^{b}$ & $0.33263^{c}$ & $0.5805^{e}$ \\
\hline \multicolumn{8}{|l|}{ Variety } \\
\hline BG & $3.34190^{\mathrm{a}}$ & $2.03308^{\mathrm{a}}$ & $1.21255^{\mathrm{a}}$ & $0.63632^{\mathrm{a}}$ & $0.605281^{\mathrm{a}}$ & $0.382649^{a}$ & $1.10906^{\mathrm{a}}$ \\
\hline KN & $2.97785^{b}$ & $1.82416^{b}$ & $1.13301^{b}$ & $0.61905^{\mathrm{a}}$ & $0.631927^{b}$ & $0.387682^{a}$ & $1.12809^{\mathrm{a}}$ \\
\hline \multicolumn{8}{|c|}{ Packing material } \\
\hline Polypropylene & $3.12860^{\mathrm{a}}$ & $1.95610^{\mathrm{a}}$ & $1.18951^{\mathrm{a}}$ & $0.63737^{\mathrm{a}}$ & $0.616686^{\mathrm{a}}$ & $0.390585^{a}$ & $1.12808^{\mathrm{a}}$ \\
\hline Polysac & $3.20156^{\mathrm{a}}$ & $1.90197^{\mathrm{a}}$ & $1.15566^{\mathrm{a}}$ & $0.61720^{\mathrm{a}}$ & $0.620236^{a}$ & $0.379038^{a}$ & $1.10764^{\mathrm{a}}$ \\
\hline
\end{tabular}

Different letters within an OJIP parameter show significant difference at $\mathrm{p}=\mathrm{v} 0.05$ level determined by Duncan mean separation
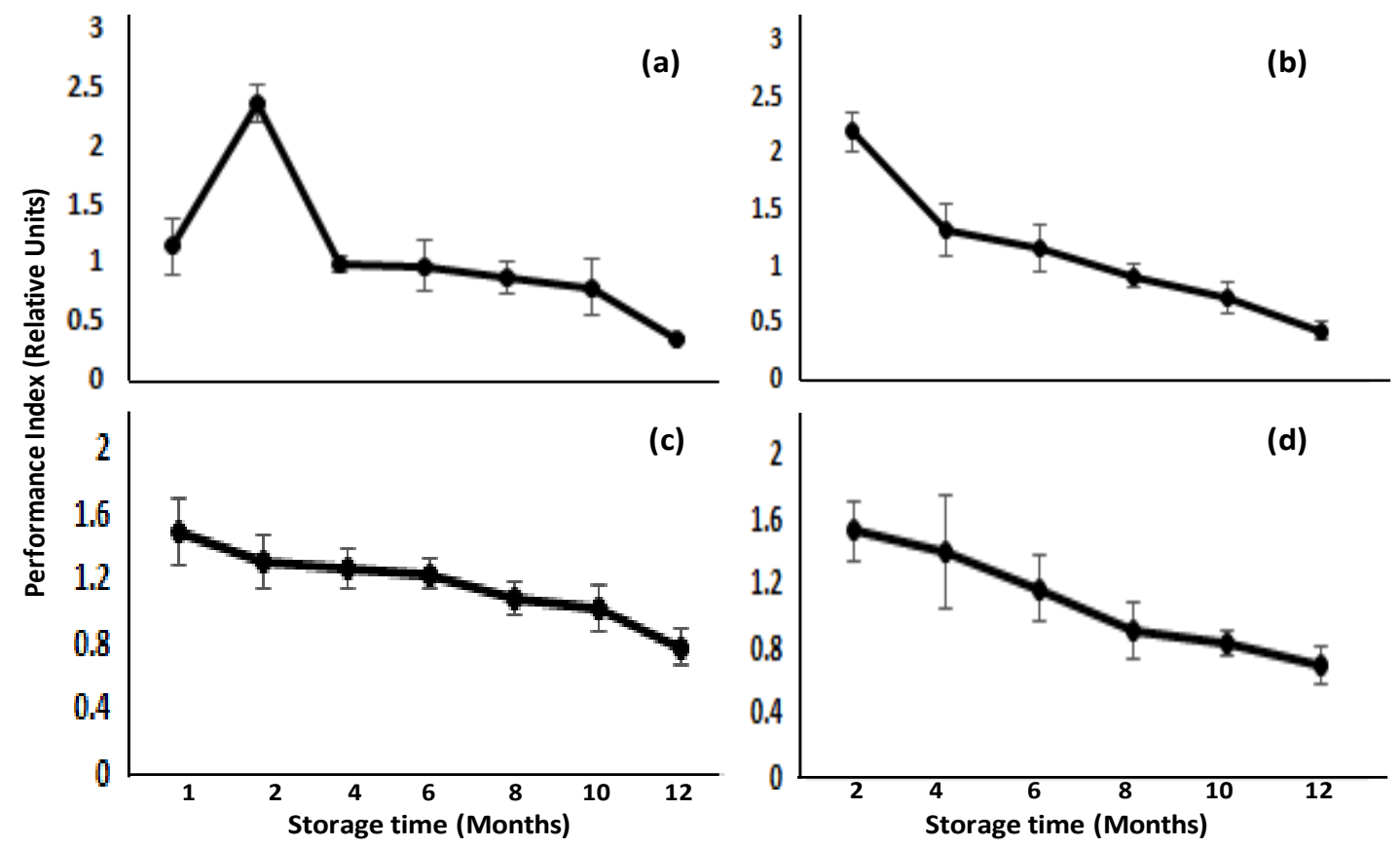

Figure 5: Performance Index (PI) measured in seedlings of two varieties of bean seeds packed in two packaging materials, during the 12-month storage period: (a and b) variety Bandarawela Green (BG); ( $c$ and d) variety Keppetipola Nil (KN); ( $a$ and c) packed in polypropylene (b and d) packed in polysac. Means \pm SEM are given. 


\section{Relationship among $\mathrm{PI}_{A B S}$, standard germination and field emergence}

Figure 6 shows the changes in germination percentage, field emergence percentage and performance index of seedlings of two varieties of bean seeds packed in two packaging materials, during the 12-month storage period. Although the germination percentage remained acceptable throughout the study period, it was apparent that the field emergence was decreased over time. The performance index was also decreased rather similar to the field emergence. Performance index was significantly positive medium correlated with the field emergence
(0.483, $\quad \mathrm{p}<.0001) \quad$ Therefore, the performance index obtained through the OJIP chlorophyll transient analysis can be used to determine the seed quality, before the field establishment with further improvement.

Therefore, it is possible to recommend OJIP chlorophyll transient analysis as a detection method for testing the vigour of seeds in comparison to other vigour testing methods. However, further studies are needed to quantify the $\mathrm{PI}_{A B S}$ to predict the seed germination in laboratory conditions, which is species specific, before seed lots are issued to the farmer.
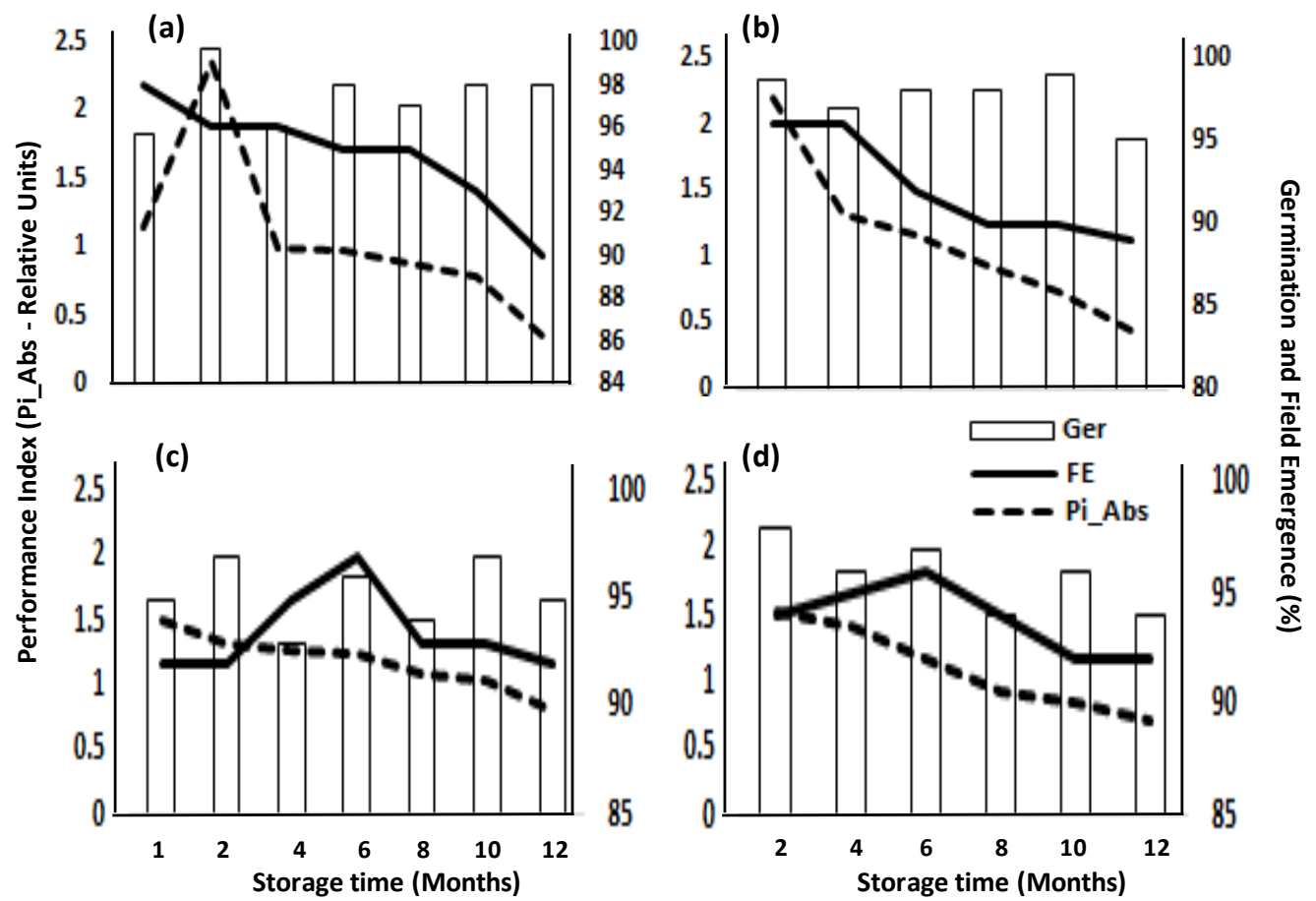

Figure 6: Change in germination percentage (vertical bars), field emergence percentage (solid line) and Performance index (dashed line) of two varieties of bean seeds packed in two packaging materials, during the 12-month storage period: ( $a$ and b) variety Bandarawela Green (BG); (c and d) variety Keppetipola Nil $(\mathrm{KN})$; ( $a$ and c) packed in polypropylene (b and d) packed in polysac.

\section{CONCLUSION}

Seed lots of two bean varieties stored over one-year period maintained their viability successfully although the field emergence was observed decreasing. $P I_{\mathrm{ABS}}$ is the most sensitive OJIP parameter out of tested parameters to evaluate the seedlings of stored seeds under the controlled temperature and relative humidity. Continuous decreasing trend in $P I_{\mathrm{ABs}}$ and correlation between performance index and field emergence is a good indicator to judge the physiological status of the seeds. Thus, OJIP chlorophyll transient analysis can be recommended as a rapid technique to test the seed vigour before the field establishment with further improvements. 


\section{REFERENCES}

Adkins, S.W., Boersma, M. and Law, M. (1996). Relationship between vigour tests and emergence of soybean when grown under a range of seedbed moisture conditions. Australian Journal of Experimental Agriculture. 36(1), 93-97.

Aliloo, A. and Shokati, B. (2011). Correlation between seed tests and field emergence of two maize hybrids (SC 704 and Sc500). Online Journal of Animal and Feed Research. 1(6), 249-254. [online] [accessed on10.06.2019] available at http://ww.ojafr.ir

Bandulasena, W.A.K.D.R., Ariyarathna, R.A.I.S, Priyantha, L. and Beneragama, C.K. (2017). Application of polyphasic OJIP chlorophyll fluorescent transient analysis in seed and seedling testing in common bean (Phaseolus vulgaris L.). Proceedings of the fourth International Conference on Post-harvest and Quality Management of Horticultural Products of Interest for Tropical Regions, Kandy, Sri Lanka. April 2017, International Society for Horticultural Sciences. pp 49.

Beneragama, C.K., Balasooriya, B.L.H.N. and Perera, T.M.R.S. (2014). Use of OJIP chlorophyll fluorescence transients to probe multiple effects of UV-C radiation on the photosynthetic apparatus of Euglena. International Journal of Applied Sciences and Biotechnology. 2(4), 553-558.

Brestic, M. and Zivcak M. (2013). PSII fluorescence techniques for measurement of drought and high temperature stress signal in plants: protocols and applications pp. 87-131. In: Rout, G.R, Das, and A.B. (eds.) Molecular stress physiology of plants. Springer, Dordrecht.

Bussotti, F., Reto, J. and Strasser, M.S. (2006). Photosynthetic behavior of woody species under high ozone exposure probed with the JIP-test: A review: Environmental Pollution. 147: 430-437. DOI:10.1016/j.envpol.2006 .08 .036 .

Cicero, S.M., van der Schoor, R. and Halink, H. (2009). Use of chlorophyll fluorescence sorting to improve soybean seed quality. Revista Brasileira de Sementes 31, 145151.[online] [accessed on 12.07.2019] available at https://dx.doi.org/10. 1590/ S0101-31222009000400017.

Dell'Aquila, A. (2009). Development of novel techniques in conditioning, testing and sorting seed physiological quality. Seed Science and Technology. 37, 608-624. DOI: https://doi.org/10.15258/sst.2009.37.3.10.

Jalink, H., Van der Schoor, R. Frandas, A., Van Pijlen, J., and Bino, R. (1998). Chlorophyll fluorescence of Brassica oleracea seeds as a non-destructive marker for seed maturity and seed performance. Seed Science Research. 8(4), 437-443. doi:10.1017/S0960258500 004402.

Kautsky, H. and Hirsch, A. (1931). Neue Versuche zur Kohlensaureassimilation. Naturwissenschaften.19, 964.DOI: 10.1007/ BF01516164.

Lawlor, D.W. and Tezara, W. (2009). Causes of decreased photosynthetic rate and metabolic capacity in water deficient leaf cells: A critical evaluation of mechanisms and integration of processes. Annals of Botany.103 (4), 561579.doi-10.1093/aob/mcn244.

Longenberger, P.S., Smith, C.W., Duke, S.E. and McMichael, B.L. (2009). Evaluation of chlorophyll fluorescence as a tool for the identification of drought tolerance in upland cotton. Euphytica. 166,25-33.

Lu, C. J., Zhang, Q., Li, L. and Cuang, T. (2001). Modification of Ph.Sy.II photochemistry in nitrogen deficient maize and wheat plants. Journal Plant Physiology. 158, 1423-1430.

McCormac, A.C., Keffe, P.D. and Draper, R.S. (1990). Automated vigour testing of field vegetables using image analysis. Seed Science and Technology. 18(1), 103-112.

Manes, F., Donato, E. and Vitale, M. (2001) Physiological response of Pinus halepensis needles under ozone and water stress conditions. Physiologia Plantarum. 113, 249257. DOI: $10.1034 /$ j.1399-3054.2001.11 30213.x

Marcos-Filho, J. (2015). Seed vigor testing: An overview of the past, present, and future perspective [online]. [Accessed on 22.08.2019]. Available at https://www. 
researchgate.net/publication/279270692. DOI: 10.1590/0103-9016-2015-0007.

Morad S. (2013). Study on some aspects on seed viability and vigour. International Journal of Advanced Biological and Biochemical Research.1(12), 1692-1693. [online] [accessed on10.06.2019] available at http://www.ijabbr.com

Nussbaum, S., Geissmann, M. Eggenberg, P. Strasser, R.J. and Fuhrer, J. (2001). Ozone sensitivity in herbaceous species as assessed by direct and modulated chlorophyll fluorescence techniques. Journal of Plant Physiology. 158, 757-766. DOI: 10.1078/0176-1617-00225.

Sako, Y., McDonald, M.B., Fujimura, K., Evans, A. F. and Bennett, M.A. (2001). A system of automated seed vigour assessment. Seed Science and Technology. 29, 625-636.

Schreiber, U., Schliwa, U. and Bilger, W. (1986). Continuous recording of photo chemical and non-photochemical chlorophyll fluorescence quenching with a new type of modulation fluorometer. Photosynthesis Research. 10,5162
Schreiber, U. (2004). Pulse amplitude modulation (PAM) Fluorometry and saturation pulse method: an overview of. In: Papageorgiou, G.C, and Govindjee. (eds) Chlorophyll a fluorescence: A signature of photosynthesis. Advances in photosynthesis and Respiration. Vlo 19, Springer, Dordrecht

Strasser, R.J., Srivastava, A. and Govindjee, G. (1995). Polyphasic chlorophyll a fluorescence transient in plants and cyanobacteria. Photochemistry and Photobiology. 61,32-42.

Strasser, R.J., Srivastava, A. and Michael, M.T. (2000). The fluorescence transient as a tool to characterize and screen photosynthetic samples. In: probing photosynthesis: Mechanism, regulation and Adaptation (M. Yunus, U.Parthre and P. Mohanty, (eds) Chapter 25, 445-483, Taylor and Francis, UK,

Strasser, R., Srivastava, A. and Govindjee, G. (2008). Polyphasic chlorophyll a fluorescence transient in plants and cyanobacteria. Photochemistry and Photobiology. 61, 32 - 42. DOI: 10.1111/j.1751-1097.1995.tb09240.x.

UNDP (2008) Fighting climate change; human solidarity in a divided world, United Nations Human Development Report, 2008. 